\title{
Controlled Growth of CdS Nanocrystals: Core/Shell viz Matrix
}

\author{
Prinsa Verma $^{1,2 *}$, Avinash C Pandey ${ }^{1}$ \\ ${ }^{1}$ Nanophosphor Application Center, Allahabad University, Allahabad, India; ${ }^{2}$ Satish Dhawan Space Center, India Space Research \\ Organization, Sriharikota, India. \\ Email: " prinsa.verma@gmail.com
}

Received March 28 ${ }^{\text {th }}, 2011$; revised May 29 ${ }^{\text {th }}, 2011$; accepted July $25^{\text {th }}, 2011$.

\begin{abstract}
The ability to precisely control the size of semiconductor nanocrystals can create an opportunity for producing functional materials with new properties, which are of importance to applications such as Light emitting diodes, biomedical diagnosis, solar cells, and spintronics. And size of nanoparticle can be controlled with efficient capping agent. For the same purpose we reported, two types of capping, one will lead to nanomatrix and other to Shelled nanostructures. Enhancement in emission intensity observed with Shell nanostructures compare to matrix. PVP is used to control the particle size, to prevent agglomeration and making thin films. A blue shift in energy level at the nanoscale is demonstrated by optical absorption. Electron microscopy studies with an SEM and TEM show a particle size of $10 \mathrm{~nm}$ and $15 \mathrm{~nm}$. We also investigated the particle size distribution of nanoparticles by small angle scattering (SAXS) study.
\end{abstract}

Keywords: Nanomatrix, Shell and Band Edge Emission

\section{Introduction}

Semiconductor quantum dots with diameters less than $10 \mathrm{~nm}$ have evoked great interest for intense investigations [1-4]. The number of atoms in such quantum dots ranges from a few tens to hundreds of atoms. These clusters of atoms exhibit the size effect with unique electronic and optical properties that depend upon the size of the cluster. The surface to bulk atom ratio also changes rapidly with size leading to drastic changes in thermal and mechanical properties [5]. A $5 \mathrm{~nm} \mathrm{CdS}$ cluster has approximately $15 \%$ of the atoms on the surfaces. The existence of this vast interface between the cluster and the surrounding medium can have a profound effect on the cluster properties [2]. As the size of CdSe particles decrease from $10 \mathrm{~nm}$ to $1 \mathrm{~nm}$, the percentage of surface atoms increases from 20 to practically $100 \%$. The surface atoms usually have unsaturated bonds or dangling bonds. These atoms have extra free energy and are more active than those in the bulk [6]. The size dependent properties appear when the radius of the particle is comparable to the Bohr radius of the exciton in the bulk material. As the particle size decreases the energy gap widens and the absorption edge shifts towards higher energy side accompanied by the appearance of a strong excitonic peak. By controlling the particle size the forbidden gap in the semiconductor can be tuned and its optical and electronic properties can be tailored so that they can be used in many applications like photocatalysis, flat panel displays, optoelectronic devices, molecular level quantum computers, single electron devices etc [7].

For controlling particle size capping is required either with organic or inorganic. A coating shell is built up around the core materials to increase their chemical stability, intensify their functions, improve their biocompatibility compared with bare core materials, and confer specific properties, such as optical, magnetic or mechanical properties on the core materials $[8,9]$. Organic and inorganic material can both used as shell material. Semiconductor nanocrystals capped with organic molecules can have a relatively large number of unpassivated surface sites as it is difficult to passivate both anionic and cationic surface sites simultaneously by these capping groups [10]. These unpassivated surface sites may act as non-radiative recombination centres which suppress their luminescence. In addition, organically capped nanocrystals have very long emission lifetimes and large Stoke shifts [11] whereas inorganically capped nanoparticles exhibit enhanced luminescence efficiencies [12] and shorter lifetimes [13]. The epitaxial growth of inorganic cap on the nanocrystals can eliminate both the anionic 
and cationic surface dangling bonds [10]. Zou, et al. [11] have studied the effectiveness of various inorganic capping agents having different band gaps on the surface passivation of cadmium sulphide (CdS) nanoparticles. They have reported that it is possible to block the nonradiative channels on the surface of these nanoparticles by capping them with wider band gap inorganic materials like $\mathrm{Cd}(\mathrm{OH})_{2}$ and zinc sulphide $(\mathrm{ZnS})$. It is also reported that $\mathrm{ZnS}$ is more effective than $\mathrm{Cd}(\mathrm{OH})_{2}$ in surface passivation because of its better charge and size compatibility with $\mathrm{CdS}$, resulting in increased band edge emission. Growth of a wide band gap semiconductor $\mathrm{ZnS}$ on the surface of a narrower band gap semiconductor CdS, forming $\mathrm{CdS} / \mathrm{ZnS}$ coreshell nanoparticles, leads to appreciable passivation resulting in enhancement of photoluminescence (PL) emission [14].

We reported synthesis of $\mathrm{Mn}^{2+}$ doped PVP-CdS nanomatrix and $\mathrm{CdS} / \mathrm{ZnS}$ core/shell nanostructures through wet chemical approach. We capped CdS with both organic and inorganic capping agents. As organic is responsible for stroke's shift where as inorganic gives better enhanced luminescence efficiencies so we can choose capping as per our requirement. After shell formation by $\mathrm{ZnS}$, monodisperse $\mathrm{CdS}$ nanoparticles were prepared, which exhibited significantly enhanced luminescence and high chemical stability. PVP role as a capping agent is already discussed in our earlier paper [15].

\section{Experiment Procedures}

\subsection{Sample Preparation}

All the reactants and solvents were analytical grade. Cadmium acetate dihydrate $\mathrm{Cd}\left(\mathrm{CH}_{3} \mathrm{COO}\right)_{2} \cdot 2 \mathrm{H}_{2} \mathrm{O}(98 \%)$, manganese acetate $\mathrm{Mn}\left(\mathrm{CH}_{3} \mathrm{COO}\right)_{2}(98 \%)$, sodium sulfide $\left(\mathrm{Na}_{2} \mathrm{~S}\right)$, zinc acetate $\mathrm{Zn}\left(\mathrm{CH}_{3} \mathrm{COO}\right)_{2}(99.99 \%)$, were purchased from Aldrich and used to synthesize or passivate the CdS:Mn nanocrystals. Each $\left(\mathrm{Cd}^{2+}, \mathrm{Zn}^{2+}, \mathrm{Mn}^{2+}\right)$ and $\mathrm{S}^{2-}$ containing standard aqueous solution was prepared by dissolving $\mathrm{Cd}\left(\mathrm{CH}_{3} \mathrm{COO}\right)_{2} \cdot 2 \mathrm{H}_{2} \mathrm{O}, \mathrm{Zn}\left(\mathrm{CH}_{3} \mathrm{COOH}\right)_{2}$, $\mathrm{Mn}\left(\mathrm{CH}_{3} \mathrm{COO}\right)_{2}$, and $\mathrm{Na}_{2} \mathrm{~S}$ in water. The concentrations of $\mathrm{Cd}^{2}, \mathrm{Zn}^{2+}$ and $\mathrm{S}^{2-}$ in water were $0.1 \mathrm{M}$ and the ratio of $\mathrm{Mn}^{2+}$ to $\mathrm{Cd}^{2+}$ was fixed to $2 \mathrm{~mol} \%$.

Here we are going to report two synthesis processes. In a typical preparation process $1.5 \mathrm{ml}$ of $0.1 \mathrm{M}$ $\mathrm{Mn}\left(\mathrm{CH}_{3} \mathrm{COO}\right)_{2}$ and $0.05 \mathrm{~g} \mathrm{PVP}$ was dissolved in $25 \mathrm{ml}$ of $0.1 \mathrm{M} \mathrm{Cd}\left(\mathrm{CH}_{3} \mathrm{COO}\right)_{2} \cdot 2 \mathrm{H}_{2} \mathrm{O}$ aqueous solution followed by $15 \mathrm{ml}$ of $0.1 \mathrm{M}$ sodium sulphide with continuous stirring until a yellow solution of PVP capped CdS nanomatrix were formed. Where as in other set 2) $1.5 \mathrm{ml}$ of $0.1 \mathrm{M}$ $\mathrm{Mn}\left(\mathrm{CH}_{3} \mathrm{COO}\right)_{2}$ and $0.05 \mathrm{~g}$ PVP was dissolved in $25 \mathrm{ml}$ of $0.1 \mathrm{M} \mathrm{Cd}\left(\mathrm{CH}_{3} \mathrm{COO}\right)_{2} \cdot 2 \mathrm{H}_{2} \mathrm{O}$ aqueous solution, then $15 \mathrm{ml}$ of $0.1 \mathrm{M}$ sodium sulphide is added followed by addition of $25 \mathrm{ml}$ of $0.1 \mathrm{M} \mathrm{Zn}\left(\mathrm{CH}_{3} \mathrm{COOH}\right)_{2}$ with continuous stirring for favourable synthesis of Core/Shell nanostructurs. Sequential addition of $\mathrm{S}^{2-}$ and $\mathrm{Zn}^{2+}$ ions to the (CdS)Mn core solution formed core/shell structures. The obtained yellow solution was stored at roomtemperature for measurements of optical absorption and photoluminescence properties. Core/shell is a result of reaction between $\mathrm{Zn}\left(\mathrm{CH}_{3} \mathrm{COOH}\right)_{2}$ and excess $\mathrm{Na}_{2} \mathrm{~S}$, which will lead to deposition of $\mathrm{ZnS}$ as a shell on the formed core CdS nanoparticle.

\subsection{Influence of Organic Capping}

Two coordinating groups, nitrogen and carboxyl are present in Poly Vinyl Pyrrolidone (PVP). Oxygen present in PVP molecule makes coordinate bond with the $\mathrm{Cd}$ ions whereas the lone pair of electrons on nitrogen in pyrrolidone is conjugated with the adjacent carbonyl group and remaining oxygen in carboxylate makes coordinate bond with the Mn ions. In PVP-CdS samples, we expect a similar bonding at the nanoparticles, where in $\mathrm{C}=\mathrm{O}-\mathrm{Cd}^{+2}$ and $\mathrm{C}=\mathrm{O}-\mathrm{Mn}^{2+}$ bonds which can give rise to overlapping of molecular orbitals of PVP with atomic orbitals of metal ions. PVP as a capping agent plays a significant role not only to increase the stability but also for the effective doping of $\mathrm{Mn}$ into the $\mathrm{CdS}$ nanophosphors, which can be attributed to the formation of coordinate bonding groups between lone pair of oxygen atoms and those of metallic atoms $\mathrm{Cd}$ and $\mathrm{Mn}$ in the $\mathrm{CdS}$ nanocomposite [15].

\subsection{Characteristics Measurements}

Transmission electron microscopic (TEM) photographs were taken on Technai 30 G2 S-Twin. Ultraviolet-visible (UV-Vis) measured on Perkin-Elmer Mc Pherson 2035, Small angle scattering pattern were obtained by a Rigaku D/max-2200 PC diffractometer operated at 40 $\mathrm{kV} / 20 \mathrm{~mA}$ and Photoluminescence spectrophotometer were measured on a Perkin-Elmer LS 55 spectrophotometer.

\section{Result and Discussion}

\subsection{TEM Analysis}

Sample preparation for TEM-Samples in mg were dissolved in ethanol and sonicated for $2 \mathrm{hrs}$ then one drop of this sample were taken on carbon coated copper grid, and it was dried in oven for $24 \mathrm{hrs}$ at $50^{\circ} \mathrm{C}$. Magnification is $200 \mathrm{KeV}$.

Figures 1(a) and (b) shows a typical TEM images of the CdS/ZnS core/shell nanoparticles and PVP-CdS nanomatrix. Nanomatrix which are shown in Figure 1(b) was estimated to be $15 \mathrm{~nm}$ but they showed non uniform distribution. Where as core/shell CdS/ZnS nanoparticles are well dispersed and estimated to be $10 \mathrm{~nm}$ (Figure 1(a)).

\subsection{UV-Vis Spectra}

Pure PVP solution exhibited nearly no absorption in the 


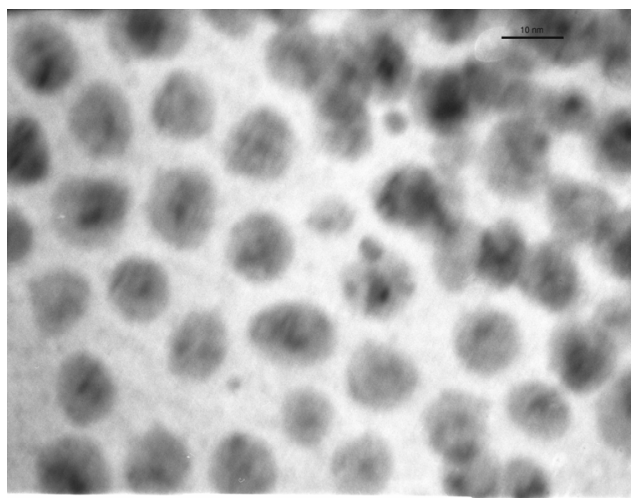

(a)

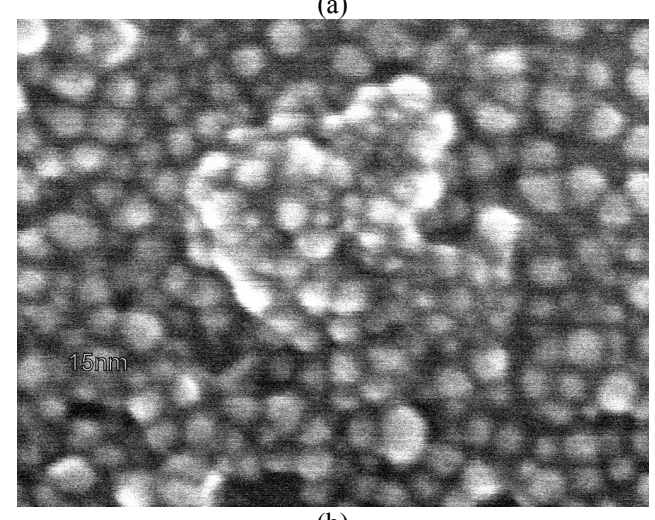

(b)

Figure 1. TEM images of (a) CdS/ZnS core/shell (b) PVPCdS matrix.

selected region. The generation of $\mathrm{CdS}$ nanoparticles could also be identified from both the color change and the UV-Vis spectrum of the as-prepared products. For bulk $\mathrm{CdS}$ and $\mathrm{ZnS}$, the absorption edges are at 500 and $335 \mathrm{~nm}$, corresponding to energy gaps 2.5 and $3.7 \mathrm{eV}$, respectively [16]. The obtained yellow solution showed an absorption onset at about $\sim 415 \mathrm{~nm}$ in nanomatrix and $\sim 400 \mathrm{~nm}$ in core/shell (Figure 2), blue shift in the absorption edge from the corresponding bulk value, implies the quantum confinement effect of the $\mathrm{CdS}$ nanoscale particles [17].

\subsection{Particle Size Distribution from SAXS Study}

Figure 3 shows the small-angle $x$-ray scattering pattern from PVP-ZnS nanomatrix and $\mathrm{CdS} / \mathrm{ZnS}$ core/shell. The scattering intensity I (s) from the nanoparticles follows the Guinier small-angle scattering intensity equation [18]:

$$
I(s)=I_{e} \cdot M \cdot n^{2} \cdot \exp \left(s^{2} \cdot R_{0} / 3\right)
$$

Here $I_{e}, M, n, s$ and $R_{0}$ are scattering intensity per electron, the number of grain, the number of electron per grain, scattering vector and inertial radius respectively. The particle size distributions of the nanoparticles could be calculated by simply plotting tangents on the curve of

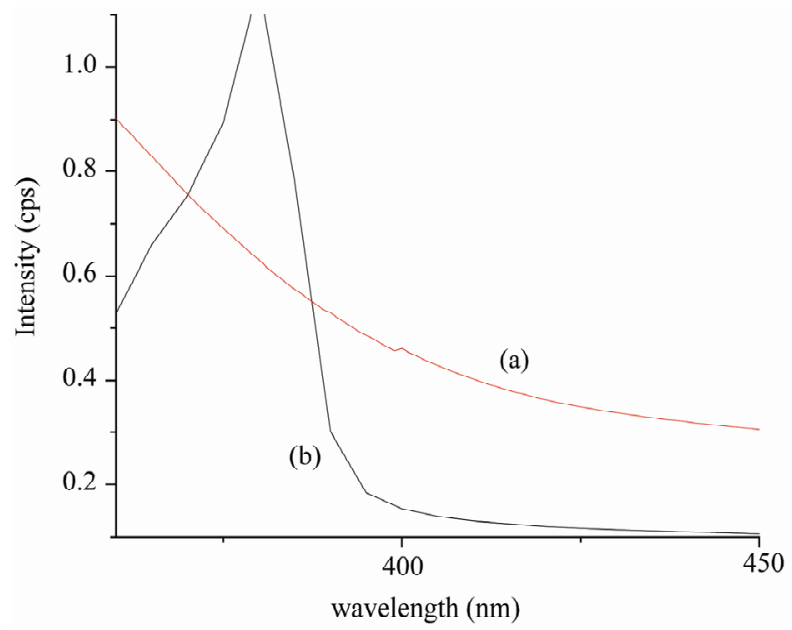

Figure 2. Uv-Vis absorption spectrum of (a) PVP-CdS matrix (b) CdS/ZnS core/shell.

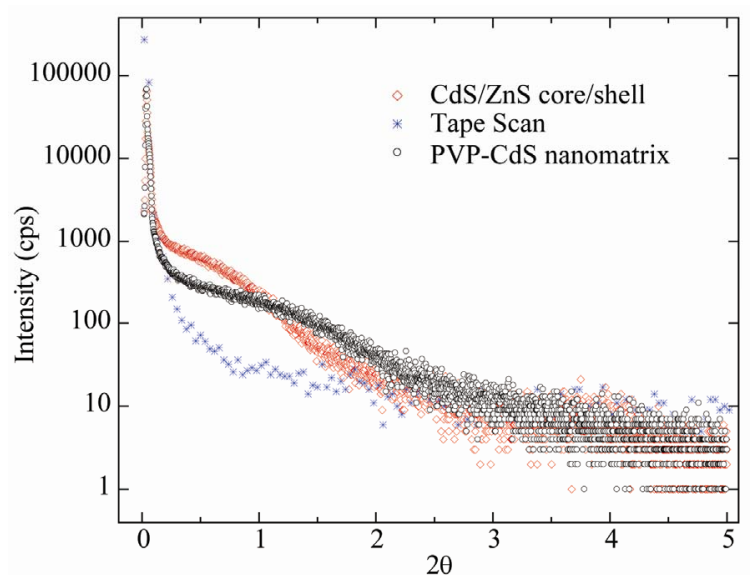

Figure 3. SAXS pattern of CdS nanoparticles.

the graph $\log$ I-s $^{2}$ ( Fankuchen Method ) [19]. Figures 4(a) and (b) shows Guinier plot of scattered intensity from the CdS/ZnS core/shell and PVP-CdS nanomatrix. Particle size distribution of $\mathrm{CdS} / \mathrm{ZnS}$ core/shell by analysis of Guinier plot of scattered intensity is $81.3 \mathrm{wt} \%$ particles of $10 \mathrm{~nm}$ size, $14.5 \mathrm{wt} \%$ particles of $19.81 \mathrm{~nm}$ and $4.2 \mathrm{wt} \%$ of $57.9 \mathrm{~nm}$. Particle size distribution of PVP$\mathrm{CdS}$ nanomatrix by analysis of Guinier plot of scattered intensity is $73.3 \mathrm{wt} \%$ particles of $15 \mathrm{~nm}$ size, $22.9 \mathrm{wt} \%$ particles of $25.39 \mathrm{~nm}$ and $3.8 \mathrm{wt} \%$ of $35.86 \mathrm{~nm}$. This particle size distribution calculation was done by grain size analysis program provided by Rigaku D/Max-2200 $\mathrm{H} / \mathrm{PC}$.

\subsection{PL Spectra}

Figure 5 shows photoluminescence spectra of the PVP$\mathrm{CdS}$ nanomatrix and $\mathrm{CdS} / \mathrm{ZnS}$ core/shell nanoparticles. $\mathrm{CdS} / \mathrm{ZnS}$ core/shell nanoparticles shows enhanced emission peak compared with PVP-CdS matrix. The strong 


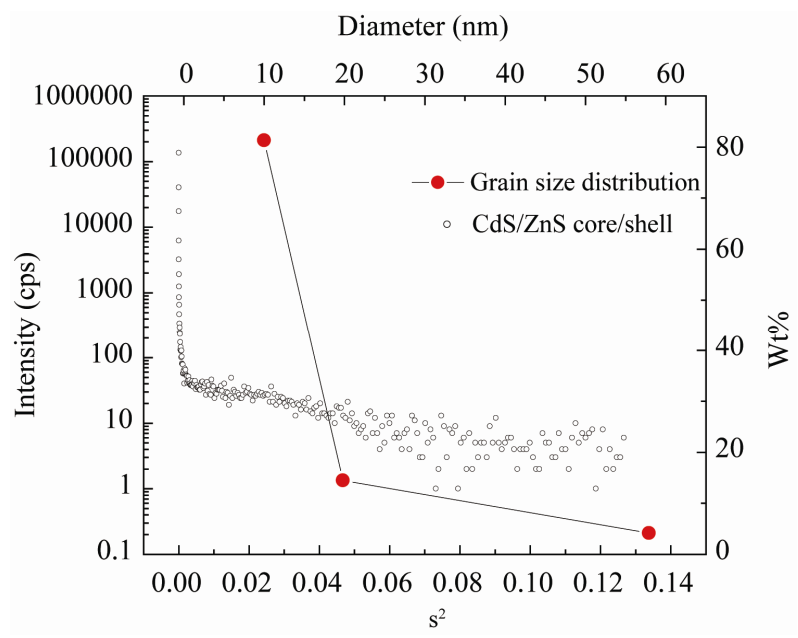

(a)

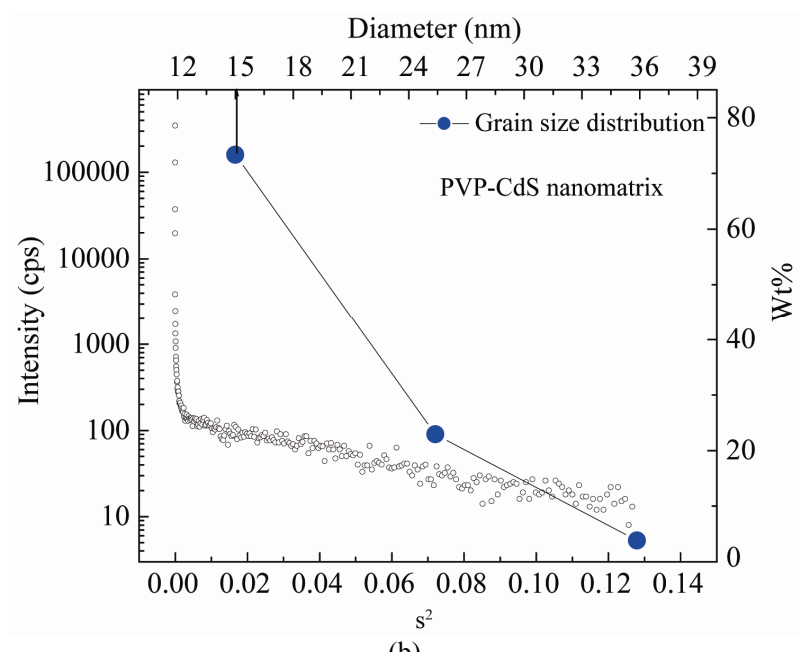

(b)

Figure 4. Guinier plot of scattered intensity from (a) CdS/ ZnS core/shell (b) PVP-CdS nanomatrix.

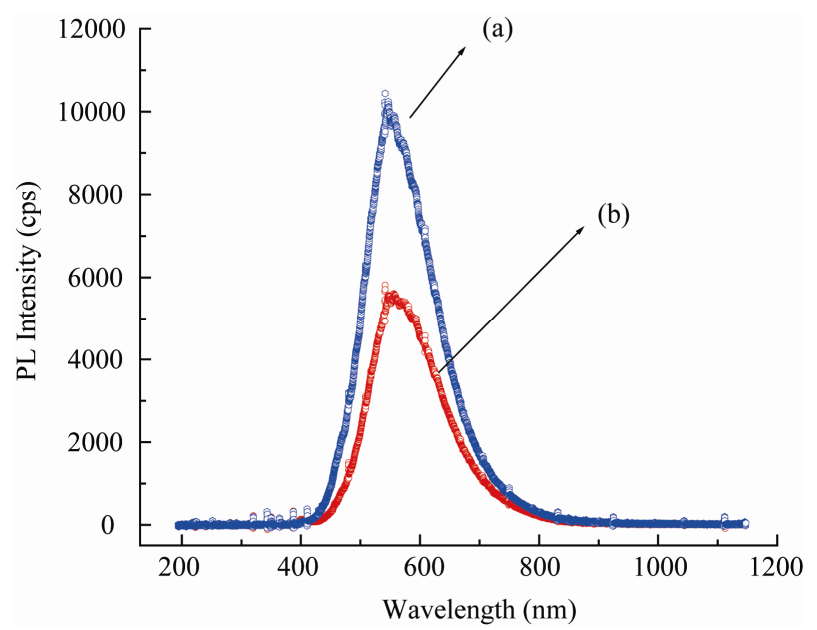

Figure 5. Photoluminescence spectra (a) CdS/ZnS core/shell (b) PVP-CdS matrix. luminescence demonstrated the influence of surface improvement. The sharpness of the emission peak showed the monodispersion of the sample [20], as also observed from TEM.

\section{Conclusions}

Our approach is to synthesis material for device purpose, having controlled growth, enhanced luminescence. The results of the studies carried out on the effect of organic and inorganic capping over $\mathrm{CdS}$ nanoparticles are presented in this article. One will lead to core/shell structures and other to matrix by simple wet chemical method. Complete coverage of the CdS core with a wider energy gap $\mathrm{ZnS}$, enhanced the PL performance of the CdS core. We also investigated the particle size distribution of $\mathrm{CdS}$ nanoparticles by small angle scattering (SAXS) study. TEM, SAXS, UV and optical characterization showed that nanoparticles showed perfect surface passivation, regular shape and well defined or nearly monodispersed nanoparticles after the inorganic shell formation over the $\mathrm{CdS}$ core compared to organically capped CdS. Efficient capping can be achieved by the proper choice of the capping agent for a given application.

\section{Acknowledgements}

The authors would like to thank all members of Nanophosphor Application Center, Allahabad University.

\section{REFERENCES}

[1] N. Herron, Y. Wang and H. Eckert, "Synthesis and Characterization of Surface-Capped, Size-Quantized CdS Clusters. Chemical Control of Cluster Size," Journal of the American Chemical Society, Vol. 112, No. 4, 1990, pp. 1322-1326. doi:10.1021/ja00160a004

[2] Y. Wang and N. Herron, "Nanometer-Sized Semiconductor Clusters: Materials Synthesis, Quantum Size Effects, and Photophysical Properties," Journal of Physical Chemistry, Vol. 95, 1991, pp. 525 -532. doi:10.1021/j100155a009

[3] L. E. Brus, "A Simple Model for the Ionization Potential, Electron Affinity, and Aqueous Redox Potentials of Small Semiconductor Crystallites,' Journal of Physical Chemistry, Vol. 79, No. 11, 1983, pp. 5566-5571. doi: $10.1063 / 1.445676$

[4] M. Nirmal and L. Brus, "Luminescence Photophysics in Semiconductor Nanocrystals," Accounts of Chemical Research, Vol. 32, No. 5, 1999, pp. 407-414. doi:10.1021/ar9700320

[5] M. Kundu, A. A. Khosravi, S. K. Kulkarni and P. Singh, "Synthesis and Study of Organically Capped Ultra Small Clusters of Cadmium Sulphide," Journal of Materials Science, Vol. 32, No. 1, 1997, pp. 245-258. doi:10.1023/A:1018520425765

[6] X. B. Chen, Y. B. Lou and C. Burda, "Spectroscopic 
Characterization of II-VI Core-Shell Nanoparticles CdSe/ CdS," International Journal of Nanotechnology, Vol. 1, No. 1-2, 2004, pp. 105-118.

[7] S. K. Kulkarni, U. Winkler, N. Deshmukh, P. H. Borse, R. Fink and E. Umbach, "Investigations on Chemically Capped CdS, ZnS and ZnCdS Nanoparticles," Applied Surface Science, Vol. 169-170, No. 1-2, 2001, pp. 438-446. doi:10.1016/S0169-4332(00)00700-5

[8] B. Saraswathi-Amma, K. Manzoor, K. Ramakrishna and M. Pattabi, "Synthesis and Optical Properties of CdS/ZnS Coreshell Nnanoparticles," Materials Chemistry and Physics, Vol. 112, No. 3, 2008, pp. 789-792. doi:10.1016/j.matchemphys.2008.06.043

[9] Y. D. Wuab and L. S. Wang, "A Novel Sonochemical Synthesis and Nanostructured Assembly of Polyvinylpyrrolidone-Capped CdS Colloidal Nanoparticles," Journal of Non-Crystalline Solids, Vol. 354, No. 26, 2008, pp. 2993-3000. doi:10.1016/j.jnoncrysol.2007.12.005

[10] X. G. Peng, M. C. Schlamp, A. V. Kadavanich and A. P. Alivisatos, "Epitaxial Growth of Highly Luminescent $\mathrm{CdSe} / \mathrm{CdS}$ Core/Shell Nanocrystals with Photostability and Electronic Accessibility," Journal of the American Chemical Society, Vol. 119, No. 30, 1997, pp. 7019-7029. doi:10.1021/ja970754m

[11] B. S. Zou, R. B. Little, J. P. Wang and M. A. El-Sayed, "Effect of Different Capping Environments on the Optical Properties of CdS Nanoparticles in Reverse Micelles," International Journal of Quantum Chemistry, Vol. 72, No. 4, 1999, pp. 439-450. doi:10.1002/(SICI)1097-461X(1999)72:4<439::AID-QU A27>3.0.CO;2-Q

[12] M. A. Hines and P. Guyot-Sionnest, "Synthesis and Characterization of Strongly Luminescing ZnS-Capped CdSe Nanocrystals," Journal of Physical Chemistry, Vol. 100, No. 2, 1996, pp. 468- 471. doi:10.1021/jp9530562
[13] A. Eychmuller, A. Hasselbarth, L. Katsikas and H. Weller, "Fluorescence Mechanism of Highly Monodisperse Q-Sized CdS Colloids," Journal of Luminescence, Vol. 48-49, No. 2, 1991, pp. 745-749. doi:10.1016/0022-2313(91)90232-K

[14] H. Yang and H. P. Holloway, "Enhanced Photoluminescence from CdS:Mn/ZnS Core/Shell Quantum Dots," Applied Physics Letters, Vol. 82, No. 12, 2003, pp. 4633 4843. doi:10.1063/1.1563305

[15] P. Verma and A. C. Pandey, "Organic Capping-Effect and Mechanism in Mn-Doped CdS Nanocomposites," Physica B: Condensed Matter, Vol. 405, No. 5, 2010, pp. 1253-1257. doi:10.1016/j.physb.2009.11.060

[16] X. C. Wu, A. M. Bittner and K. Kern, "Synthesis, Photoluminescence and Adsorption of CdS/Dendrimer Nanocomposites," Journal of Physical Chemistry B, Vol. 109, No. 1, 2005, pp. 230-239. doi:10.1021/jp046072k

[17] A. Z. Malik, P. O’Brien and N. Revaprasadu, "Synthesis of TOPO-Capped Mn-doped $\mathrm{ZnS}$ and CdS Quantum Dots," Journal of Material Chemistry, Vol. 11, No. 9, 2001, pp. 2382-2386. doi: $10.1039 / \mathrm{b} 102709 \mathrm{n}$

[18] A. Guinier and G. Fournet, "Small Angle Scattering of Xrays," Journal of Polymer Chemistry, Vol. 19, No. 93, 1956, p. 594.

[19] L. E. Alexander, "X-ray Diffraction Methods in Polymer Science," Journal of Polymer Science Part B: Polymer Letters, Vol. 9, No. 8, 1970, pp. 635-636.

[20] S. Sapra, J. Nanda, D. D. Sarma, F. A. El-Al and G. Hodes, "Blue Emission from Cysteine Ester Passivated Cadmium Sulfide Nanoclusters," Chemical Communications, Vol. 21, 2001, pp. 2188-2189. doi:10.1039/b106420g 